\title{
Generating spatial precipitation ensembles: impact of temporal correlation structure
}

\author{
O. Rakovec ${ }^{1}$, P. Hazenberg ${ }^{1,}{ }^{*}$, P. J. J. F. Torfs ${ }^{1}$, A. H. Weerts ${ }^{2}$, and R. Uijlenhoet ${ }^{1}$ \\ ${ }^{1}$ Hydrology and Quantitative Water Management Group, Department of Environmental Sciences, Wageningen University, \\ Wageningen, The Netherlands \\ ${ }^{2}$ Deltares, P.O. Box 177, 2600 MH Delft, The Netherlands \\ *now at: Atmospheric Sciences Department, The University of Arizona, Tucson, AZ, USA
}

Correspondence to: O. Rakovec (olda.rakovec@wur.nl)

Received: 27 February 2012 - Published in Hydrol. Earth Syst. Sci. Discuss.: 12 March 2012

Revised: 22 August 2012 - Accepted: 23 August 2012 - Published: 24 September 2012

\begin{abstract}
Sound spatially distributed rainfall fields including a proper spatial and temporal error structure are of key interest for hydrologists to force hydrological models and to identify uncertainties in the simulated and forecasted catchment response. The current paper presents a temporally coherent error identification method based on time-dependent multivariate spatial conditional simulations, which are conditioned on preceding simulations. A sensitivity analysis and real-world experiment are carried out within the hilly region of the Belgian Ardennes. Precipitation fields are simulated for pixels of $10 \mathrm{~km} \times 10 \mathrm{~km}$ resolution. Uncertainty analyses in the simulated fields focus on (1) the number of previous simulation hours on which the new simulation is conditioned, (2) the advection speed of the rainfall event, (3) the size of the catchment considered, and (4) the rain gauge density within the catchment. The results for a sensitivity analysis show for typical advection speeds $>20 \mathrm{~km} \mathrm{~h}^{-1}$, no uncertainty is added in terms of across ensemble spread when conditioned on more than one or two previous hourly simulations. However, for the real-world experiment, additional uncertainty can still be added when conditioning on a larger number of previous simulations. This is because for actual precipitation fields, the dynamics exhibit a larger spatial and temporal variability. Moreover, by thinning the observation network with $50 \%$, the added uncertainty increases only slightly and the cross-validation shows that the simulations at the unobserved locations are unbiased. Finally, the first-order autocorrelation coefficients show clear temporal coherence in the time series of the areal precipitation using the time-dependent multivariate conditional simulations, which was not the case us-
\end{abstract}

ing the time-independent univariate conditional simulations. The presented work can be easily implemented within a hydrological calibration and data assimilation framework and can be used as an improvement over currently used simplistic approaches to perturb the interpolated point or spatially distributed precipitation estimates.

\section{Introduction}

Precipitation is the most dominant input term determining the hydrological response at the catchment scale (Beven, 2001). Historically, spatial precipitation information was obtained by rain gauge measurements based on point scale estimates. However, during the last decades, application of weather radar at larger scales has improved our understanding of the spatial and temporal properties of rainfall even further. Unfortunately, precipitation estimates by weather radar are prone to errors (e.g. Seo et al., 1999; Steiner et al., 1999; Krajewski and Smith, 2002; Seo and Breidenbach, 2002; Germann et al., 2009; Hazenberg et al., 2011). To date, this implies that operational nowcasting/forecasting systems have to make use of rain gauge information to mitigate the errors in radar rainfall estimates (e.g. Schuurmans et al., 2007; Goudenhoofdt and Delobbe, 2009; Cole and Moore, 2009). As such, rain gauges remain an important tool for the derivation of unbiased spatially distributed rainfall estimates.

To obtain sound spatially distributed rainfall information from rain gauge observations, these devices generally are interpolated to appropriate spatial and temporal resolutions, 
depending on the hydrological purpose. Among interpolation methods, geostatistical techniques (like kriging) are popular. These methods take into account information about the spatial variation within an area and provide both a mean rainfall as well as an associated error estimate (Webster and Oliver, 2001; Schuurmans and Bierkens, 2007). These errors in areal rainfall are of key interest for hydrologists because they can be used to estimate uncertainties in catchment response. An evaluation of those errors in a spatially lumped manner has been discussed, for example, by Zawadzki (1973) and Willems (2001). We refer to Villarini et al. (2008) and Ciach and Krajewski (2006) and references cited therein, for analyses of different spatial and temporal sampling errors from a rain gauge perspective.

Nevertheless, kriging is prone to smooth local variability of rainfall. Further away from observation points, high (low) values tend to be underestimated (overestimated) (Goovaerts, 1997). These biases decrease the usability of kriging in applications sensitive to extreme values (Goovaerts, 1997), such as within spatially distributed rainfall-runoff modelling (Bivand et al., 2008).

Sound spatial and temporal estimates of precipitation and its corresponding uncertainty are of key interest for both scientific and applied hydrological studies (Liu et al., 2012). The generation of an ensemble, which is a finite and discrete number of spatial realisations over time, is able to realise this goal. A common practice in hydrological data assimilation applications to obtain ensembles is to perturb the interpolated point or spatially distributed estimates by Gaussian white noise with a standard deviation ranging between $15-50 \%$ of the observed precipitation (e.g. Pauwels and De Lannoy, 2006; Weerts and El Serafy, 2006). Although this approach leads to hydrological model simulations with wide discharge uncertainty bands, the realisations are not very realistic from a hydro-meteorological perspective, because of a lack in coherent temporal evolution of each individual precipitation realisation.

Sound spatially distributed rainfall fields including a proper spatial error structure can be obtained by conditional simulation. Unlike interpolation this technique provides both the best local estimate and ensures that realisations match the sample statistics and are conditional on neighbouring estimates. In other words, conditional simulations provide proper information about the spatial uncertainty (Goovaerts, 1997). Several hydrological studies have applied conditional simulations at daily (e.g. Clark and Slater, 2006; Schuurmans, 2008; Vischel et al., 2009; Grimes and Pardo-Iguzquiza, 2010) and at hourly time steps (AghaKouchak et al., 2010; Renard et al., 2011).

Unfortunately, conditional simulations do not primarily take the temporal evolution of the spatial field into account (Goovaerts, 1997; Webster and Oliver, 2001; Bivand et al., 2008). Nevertheless, for precipitation the temporal correlation structure can be an important aspect to be considered when generating spatial precipitation ensembles. Theoreti- cally, this can be achieved using spatial conditional simulations which are made conditional on previous simulations. Neglecting this temporal aspect would lead to underestimation of the overall uncertainty in precipitation ensembles.

The objective of this study is to define a plausible precipitation ensemble generator using rain gauges to capture the temporal coherence for each realisation of a sequence of spatial rainfall fields at an hourly time step. Our analyses focus on the uncertainty in the simulated fields based on (1) the number of previously simulated hours on which the new simulation is conditioned, (2) the advection speed of the rainfall event, (3) the size of the catchment considered and (4) the rain gauge density within the catchment. Our goal is to present a technique, which can be easily implemented within a hydrological data assimilation framework to be used as an improvement over currently used simplistic approaches to perturb the interpolated point or spatially distributed estimates. The advantage of having the temporal coherence in hydrological model states is that it avoids the necessity to smooth possible extreme state values, which can occur when neglecting temporal coherence.

\section{Material and methods}

\subsection{Data}

Hourly precipitation data are available from 42 automatic rain gauges situated within the Belgian Ardennes region (Fig. 1). This moderately hilly terrain with maximum elevations of $\sim 700 \mathrm{~m}$ a.m.s.l. is predominantly drained by the Meuse River and partly by the Rhine River (Berne et al., 2005; Driessen et al., 2010).

In this paper, we focus on the analysis of three representative stratiform winter rainfall events as described and analysed by Hazenberg et al. (2011): (1) a fast-moving stratiform system (22 October 2002), (2) a large-scale stratiform system (22 December 2002) and (3) a fast-moving frontal stratiform system (1 January 2003). For a further description of these events, the reader is referred to Hazenberg et al. (2011). The main characteristics of these events are given in Table 1. Additionally, the autocorrelation coefficients of the catchment average precipitation of the Upper Ourthe $\left(1600 \mathrm{~km}^{2}\right)$ for 30 rainy events with a minimum duration of $13 \mathrm{~h}$ are presented in Fig. 2. All 30 events were observed during the winter half year, from 1 October 2002 to 31 March 2003. Figure 2 shows that the temporal memory of the precipitation is highly significant (decorrelation time between 2 and $3 \mathrm{~h}$ ) and that the autocorrelation roughly follows an exponential decay.

\subsection{Geostatistical analysis}

The variogram is a geostatistical measure of spatial variability in terms of the semi-variance over a lag distance $h$. The experimental omnidirectional semi-variogram, which 


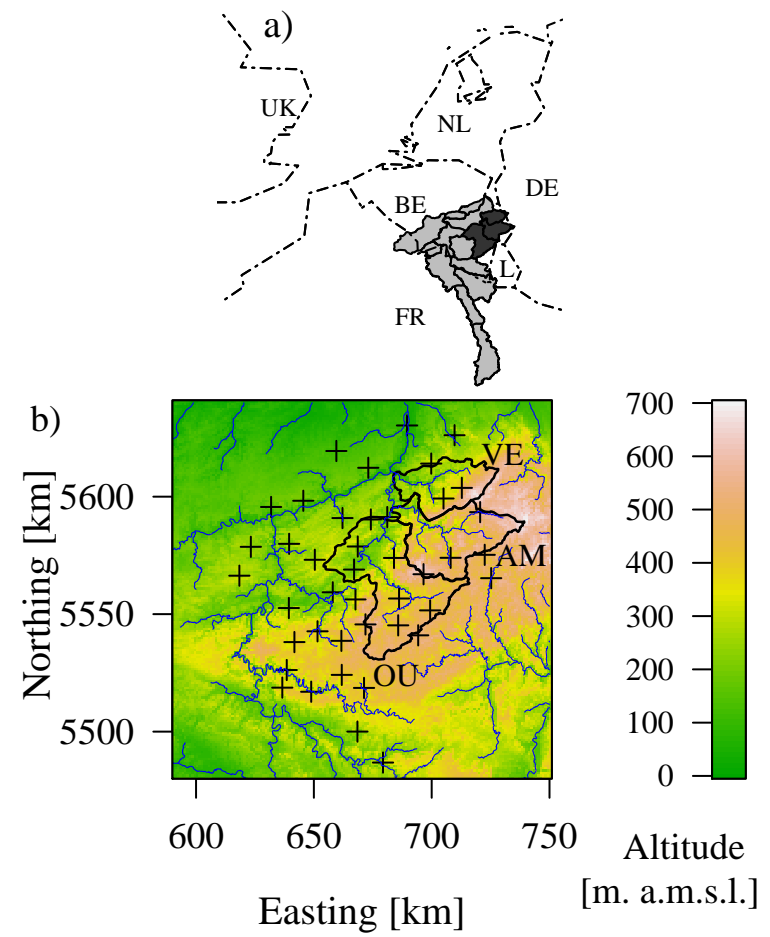

Fig. 1. (a) The Meuse River basin upstream of Borgharen $\left(\sim 21000 \mathrm{~km}^{2}\right)$, the entrance point into the Netherlands, and its 15 sub-catchments (grey polygons) including the Upper Ourthe, Amblève and Vesdre sub-catchments (black polygons). (b) Topographic map of the Belgian Ardennes including the Upper Ourthe (OU), Amblève (AM) and Vesdre (VE) sub-catchments, the channel network (blue lines), and rain gauges (plusses). Projection is in the Universal Transverse Mercator (UTM) $31 \mathrm{~N}$ coordinate system. After Hazenberg et al. (2011).

is generally called the variogram, assumes stationarity and isotropy of the predicted variable. It represents half of the mean square difference between paired data values (i.c. measured precipitation) within the same binned lag distance $h$ :

$\hat{\gamma}(h)=\frac{1}{2 N_{h}} \sum_{k=1}^{N_{h}}\left(z\left(x_{k}\right)-z\left(x_{k}+h\right)\right)^{2}$,

where $N_{h}$ is the number of data observation pairs and $z\left(x_{k}\right)$ and $z\left(x_{k}+h\right)$ are the observations separated by the lag distance $h$. Because the experimental variogram is derived only for several discrete lag distances, a parametric variogram model has to be fitted in order to obtain continuous estimates of the semi-variance.

The spherical model is a popular and widely employed variogram model for rainfall (Berne et al., 2004; Schuurmans et al., 2007; van de Beek et al., 2011; Verworn and Haberlandt, 2011). With only three parameters it is defined

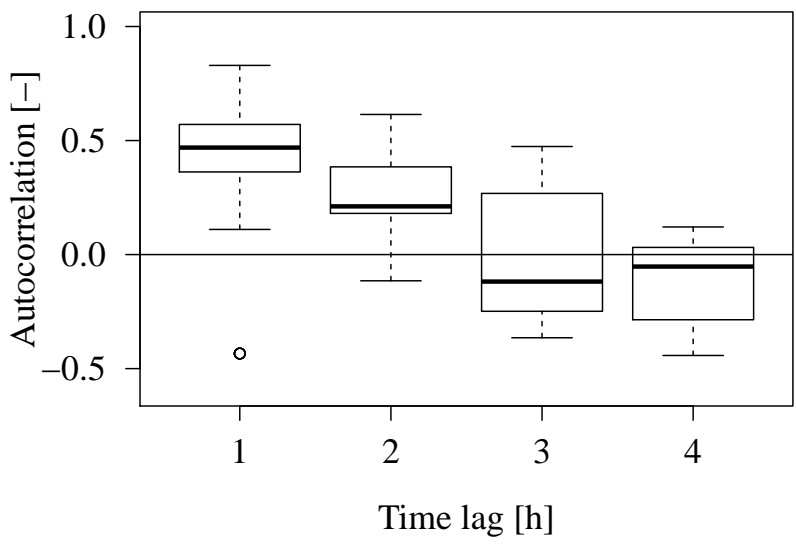

Fig. 2. Autocorrelation coefficients of the catchment averaged precipitation of the Upper Ourthe for 30 rainy events between $1 \mathrm{Oc}$ tober 2002 and 31 March 2003. The bold black line in the boxplot is the median, the body of a boxplot shows the interquantile range (Q75-Q25) and the whiskers represent the sample minima and sample maxima, unless the extreme value occurs further than 1.5 times the interquartile range from the box, in which case the outlier is shown by a dot.

as follows:

$\gamma(h)= \begin{cases}c_{0}+c_{1}\left(\frac{3 h}{2 a}-\frac{1}{2}\left(\frac{h}{a}\right)^{3}\right) & \text { if } h \leq a \\ c_{0}+c_{1} & \text { if } h>a .\end{cases}$

In Eq. (2), the parameter $c_{0}$ is the nugget, representing the semi-variance at distance $h=0$. The parameter $c_{1}$ is the partial sill, while $a$ represents the range, the distance beyond which the data are not correlated any more.

Certainly, the choice of variogram model involves some subjectivity. Since our main interest is to see how the temporal aspect (i.e., the temporal correlation structure) affects the uncertainty in simulated fields, we decided to keep the parametrisation as simple as possible. However, since we are focusing specifically on the added uncertainty that originates due to the advection of a precipitation cell, we expect these results not to change radically if another variogram model would have been chosen. Additionally, the spatial anisotropy was not considered in the variogram model. Although this is certainly a relevant issue, it is beyond the scope of the current study.

Figure 3 shows two examples of the experimental variogram as well as the fitted spherical model for two consecutive hours on 22 December 2002. Note that the unit of semivariance is in $\mathrm{mm}$ instead of $\mathrm{mm}^{2}$. This is because the quantitative statistical measures, which are employed in this study, are particularly suitable for normally distributed data. However, rainfall by nature does not follow a Gaussian distribution at shorter time scales. Therefore, a pragmatic and popular solution to overcome this problem is to transform the rainfall data such that their distribution approaches a Gaussian distribution. As such, rainfall data are square-root 
Table 1. Characteristics of three representative rainfall events.

\begin{tabular}{lrrrr}
\hline Starting time & $\begin{array}{r}\text { Duration } \\
{[\mathrm{h}]}\end{array}$ & $\begin{array}{r}\text { Speed }^{\mathrm{a}} \\
{\left[\mathrm{km} \mathrm{h}^{-1}\right]}\end{array}$ & $\begin{array}{r}\text { Mean }^{\mathrm{b}} \\
{[\mathrm{mm}]}\end{array}$ & $\begin{array}{r}\text { St. dev. }^{\mathrm{c}} \\
{[\mathrm{mm}]}\end{array}$ \\
\hline 22 Oct 2002 & 10 & 54 & 12.2 & 7 \\
22 Dec 2002 & 10 & 21 & 16.3 & 3.9 \\
1 Jan 2003 & 10 & 33 & 17.5 & 5 \\
\hline
\end{tabular}

a The advection speed for the three precipitation events was obtained by estimating the mean speed of the precipitation system during the event. We identified the precipitation system based on observed volumetric radar data for which the reflectivity exceeded $7 \mathrm{dBZ}\left(\sim 0.1 \mathrm{~mm} \mathrm{~h}^{-1}\right)$. ${ }^{\mathrm{b}}$ Mean of the precipitation sums for all 42 rain gauges. ${ }^{c}$ Standard deviation of the 42 precipitation sums.

transformed (Schuurmans et al., 2007; van de Beek et al., 2011).

Additionally, Eq. (1) can be extended for the timedependent multivariate case, which relates spatial dependency between two variables $z_{\mathrm{p}}$ and $z_{\mathrm{q}}$ (subindices "p" and " $\mathrm{q}$ " stand for the time steps) and yields the cross variogram:

$$
\begin{aligned}
\hat{\gamma}_{\mathrm{pq}}(h)= & \frac{1}{2 N_{h}} \sum_{k=1}^{N_{h}}\left[\left(z_{\mathrm{p}}\left(x_{k}\right)-z_{\mathrm{p}}\left(x_{k}+h\right)\right)\right. \\
& \left.\left(z_{\mathrm{q}}\left(x_{k}\right)-z_{\mathrm{q}}\left(x_{k}+h\right)\right)\right] .
\end{aligned}
$$

This property is defined as half the expectation of the product of the increments of two variables (Wackernagel, 2003). Obviously, if $z_{\mathrm{p}}=z_{\mathrm{q}}=z$, then Eq. (3) reduces to Eq. (1). Figure 3 shows an example of an experimental cross-variogram and the fitted spherical model. Interpretations of direct and cross-variograms will be discussed in Sect. 3.1.

The gstat $\mathrm{R}$ package function fit.lmc() was employed to fit the direct and cross variogram models using weighted least square fitting (Pebesma, 2004). The default method uses weights $N_{h} / h^{2}$. The initial model parameters of the spherical variogram model were set as follows: $c_{1}=0.1 \mathrm{~mm}, a=70 \mathrm{~km}$ and $c_{0}=0.02 \mathrm{~mm}$. Function fit. $1 \mathrm{mc}()$ also ensures that the system is positive definite (Pebesma, 2004).

\subsection{Conditional simulation}

Conditional simulation is a geostatistical method, which generates multiple realisations that all reasonably match the sample statistics (variogram model) and exactly match the conditioning data (Goovaerts, 1997). As such, conditional simulation is a useful tool to model and quantify spatial uncertainty of a variable such as precipitation (e.g. Clark and Slater, 2006; Schuurmans, 2008; Vischel et al., 2009; AghaKouchak et al., 2010; Grimes and Pardo-Iguzquiza, 2010; Renard et al., 2011). Time-independent univariate conditional simulations depend on the spatial observations by rain gauges for a given simulation hour. However, by performing timedependent multivariate conditional simulations, it becomes possible to simulate rainfall fields conditional on both previously simulated precipitation fields as well as on the rain-

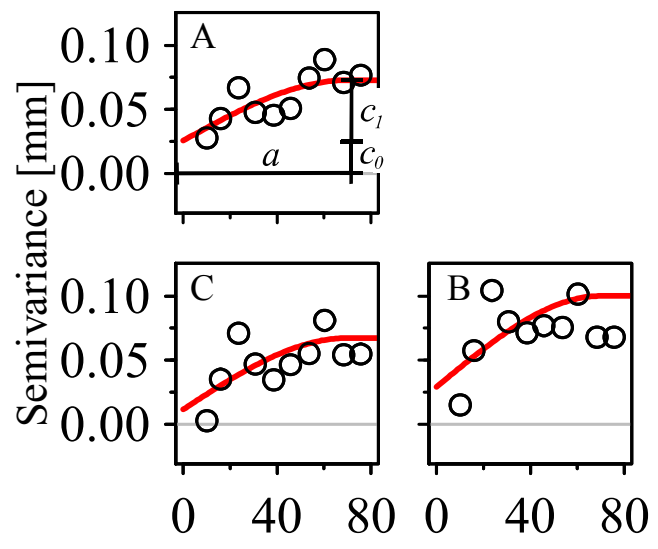

Distance $[\mathrm{km}]$

Fig. 3. Two examples of an experimental variogram (black circles) and the fitted spherical variogram model (red curve) of square-root transformed rain gauge observations on 22 December 2002 for two consecutive hours (A and B). (C) Experimental cross-variogram (circles) and fitted spherical cross-variogram model corresponding to $(\mathbf{A})$ and $(\mathbf{B})$.

fall observations by rain gauges. This approach enables to introduce temporal coherence for each simulated grid point over time.

In the current study, the gstat R package (Pebesma, 2004; Rossiter, 2007; R Development Core Team, 2011) was used to simulate conditional precipitation fields. For a comprehensive overview of the theory behind conditional (sequential Gaussian) simulations we refer to Goovaerts (1997). Here, only a brief summary is presented:

Initially, a normal transformation of rainfall data is carried out. Then, the simulation is performed on the transformed dataset according to following steps (Goovaerts, 1997):

1. A random path throughout all the grid nodes is defined, where all nodes are visited only once.

2. At each grid note, given the variogram model, a random number is drawn from a Gaussian distribution with parameters equal to the kriging prediction and variance. This number is added to the dataset used to condition the subsequently simulated grid nodes.

3. After an estimate is obtained for all grid nodes, the back-transformation of the simulated normal values to the original rainfall distribution is performed.

By performing these steps, one time-independent univariate ensemble realisation per time step is generated. Other realisations can be obtained using different random paths over the simulation grid domain.

For the purpose of computational stability, we further focus on rainy periods, which are defined as a cluster of consecutive rainy hours, for which each individual hour satisfies 
a minimal intensity condition. More specifically, the mean of all rain gauge observations should have at least a minimum value of $0.1 \mathrm{~mm}$ and the maximum individual observation has to exceed $0.5 \mathrm{~mm}$. Additionally, to prevent computational instability, rain gauges with zero rainfall are set to a small value of $0.05 \mathrm{~mm}$.

Then, time-dependent multivariate conditional simulations are carried out for each rainy period according to the following steps:

1. Initially, $N$ ensemble realisations conditional on the rain gauge data and the variogram model are simulated for the first hour of each rainy period (time-independent univariate conditional simulation).

2. For the following simulation hours, the multivariate simulation for realisation $j$ and time $t$ is conditioned on: (a) rain gauge observations at time $t$ given the fitted direct variogram model and (b) previously simulated realisations $j$ at times $(t-1, \ldots, t-M)$, where $M$ is simulation memory, given the cross-variogram models. This means that the observed precipitation by rain gauges at times $(t-1, \ldots, t-M)$ is substituted by the simulated fields, which encounter all the points of the entire simulation grid.

\subsection{Mathematical notation}

Throughout this paper, the following notations are used. A time series of rainfall realisations at the $n$-th pixel to be simulated is defined using the following matrix:

$\mathbf{R}_{j, t}^{n, m}=\left(\begin{array}{cccc}R_{1,1} & R_{1,2} & \cdots & R_{1, T} \\ R_{2,1} & R_{2,2} & \cdots & R_{2, T} \\ \vdots & \vdots & \ddots & \vdots \\ R_{J, 1} & R_{J, 2} & \cdots & R_{J, T}\end{array}\right)$

where $m$ is the simulation memory scenario, $j$ is an index of the ensemble realisation and $t$ stands for time. $J$ is the ensemble size and $T$ is the duration of the rainy period.

In general, two types of approaches can be used to disentangle the uncertainty in variability. The first way of looking at one precipitation realisation is to evaluate and quantify its corresponding statistics for the whole rainfall event. The variability of a single realisation over time during an event (bold line in Fig. 4), giving rise to uncertainty in the accumulated rainfall, is a typical source of uncertainty dealt with by hydrometeorologists (e.g. Mandapaka et al., 2010; Kirstetter et al., 2010), catchment hydrologists and rainfall-runoff modellers (e.g. Brauer et al., 2011). An alternative approach is to quantify the uncertainty across the ensemble for each individual time step ( $\square$ in Fig. 4), which is more of interest for hydrologists employing Kalman filtering approaches in flood forecasting (e.g. Weerts and El Serafy, 2006; Clark et al., 2008).

Having defined the $\mathbf{R}$ matrix according to Eq. (4), we can derive the first two central moments of $\mathbf{R}$ from two different

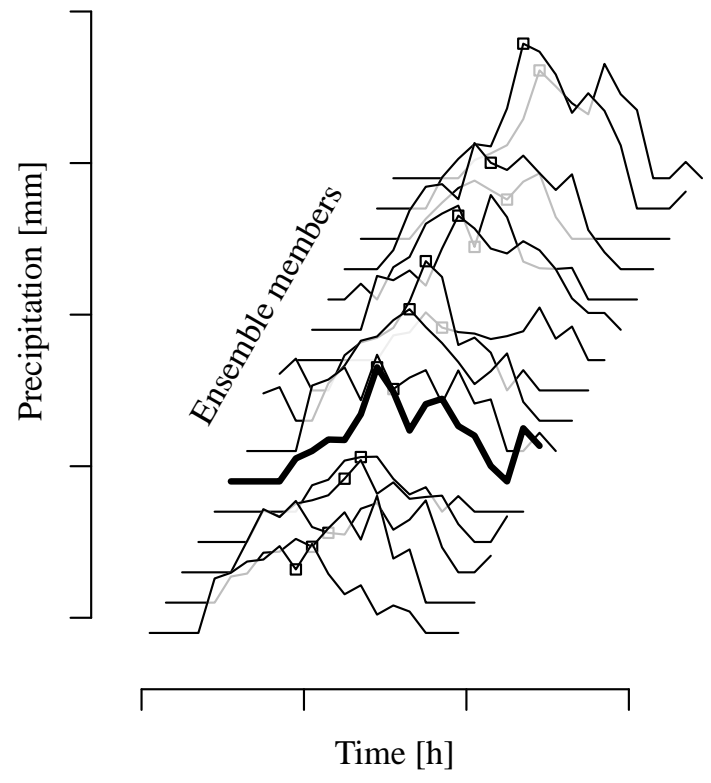

Fig. 4. Two types of evaluating the statistics of precipitation ensembles: hydrological event-based approach (bold line for one ensemble realisation) and data assimilation across-ensemble approach ( $\square$ for one time instant).

perspectives: (1) across-ensemble (having index $J$, Eqs. 5 and 6) and (2) event-based (along the time axis having index $T$, Eqs. 7 and 8):

$\hat{\mu}_{J, t}[\mathbf{R}]=\frac{1}{J} \sum_{j=1}^{J} R_{j, t}$

$\hat{\sigma}_{J, t}^{2}[\mathbf{R}]=\frac{1}{J} \sum_{j=1}^{J}\left(R_{j, t}-\hat{\mu}_{J, t}[\mathbf{R}]\right)^{2}$

$\hat{\mu}_{T, j}[\mathbf{R}]=\frac{1}{T} \sum_{t=1}^{T} R_{j, t}$

$\hat{\sigma}_{T, j}^{2}[\mathbf{R}]=\frac{1}{T} \sum_{t=1}^{T}\left(R_{j, t}-\hat{\mu}_{T, j}[\mathbf{R}]\right)^{2}$.

The uncertainty within the precipitation ensemble can be expressed by the coefficient of variation $(\mathrm{CV})$, the ratio of the standard deviation of the dataset to its mean, which represents a normalised dispersion and enables comparison between the generated ensembles for different scenarios (e.g. Wackernagel, 2003):

$\mathrm{CV}=\frac{\hat{\sigma}}{\hat{\mu}}$. 


\subsection{Experimental setup}

\subsubsection{Interpretation of direct and cross variograms}

To understand how the direct and cross-variograms reflect the differences in spatial variability between different precipitation fields, two examples of experimental and modelled variograms are analysed for the case of a synthetic circularshaped rainfall cell moving over a $145 \mathrm{~km} \times 145 \mathrm{~km}$ grid with $1 \mathrm{~km} \times 1 \mathrm{~km}$ resolution (Fig. 5). As part of this case, the effect of rain gauge density on the experimental and modelled variograms is addressed and includes sampling either from all 21025 grid pixels (a very dense synthetic observation network) or using only the 42 rain gauge pixels (actual real-world network). As such, both the impacts of using a sparse gauge network and of temporal correlation can be identified.

\subsubsection{Conditional simulations: sensitivity analysis}

Next in this study, sensitivity analyses are carried out for a number of scenarios, which enable one to obtain better understanding of individual contributions of uncertainty in the synthetic simulated fields. The sensitivity analyses encompass four aspects:

1. Time: eight types of simulations with, given the time lag, simulation memories of $0-7 \mathrm{~h}$.

2. Advection speed: five synthetic circular-shaped rainfall cells with an area of about $4100 \mathrm{~km}^{2}(72.5 \mathrm{~km}$ diameter), an intensity of $2 \mathrm{~mm} \mathrm{~h}^{-1}$ and moving at different advection speeds of $6,8,11,17,25 \mathrm{~km} \mathrm{~h}^{-1}$ over the simulation domain (Fig. 5). The duration of the rainfall events is $18,12,9,6$ and $4 \mathrm{~h}$, respectively. As such, the dimensions of these synthetic rainfall cells are similar to those observed within the region (Hazenberg et al., 2011).

3. Area: six synthetic nested sub-catchments over which the analysis is carried out (Fig. 6a).

4. Observation density: three types of rain gauge densities (Fig. 6b): (1) the actual observation network consists 27 rain gauges, (2) the reduced network has 14 rain gauges and (3) the complete synthetic network has 100 rain gauges. Removal of the rain gauges from the actual observation network follows a method (Goudenhoofdt and Delobbe, 2009), which keeps the spatial distribution of remaining gauges as uniform as possible. First, the sum of the inverse distances between the four nearest gauges is calculated for each gauge and then half of the gauges with the highest values are removed. The complete synthetic network for the catchment's pixels without any real rain gauge is obtained by randomly drawing $\mathrm{x}$ - and $\mathrm{y}$-coordinates from a uniform distribution.
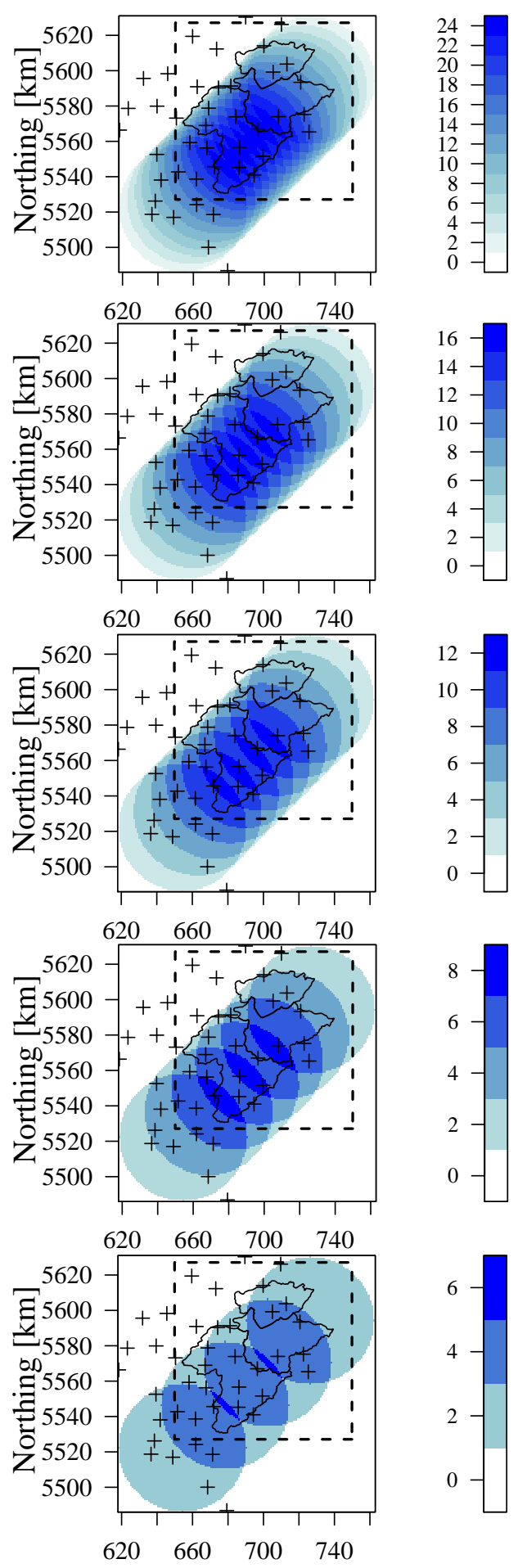

Easting $[\mathrm{km}]$

Fig. 5. Sensitivity analysis. Five synthetic rainfall events of circular shape with an intensity of $2 \mathrm{~mm} \mathrm{~h}^{-1}$ and advection speeds of 6,8 , $11,17,25 \mathrm{~km} \mathrm{~h}^{-1}$ and durations of $18,12,9,6$ and $4 \mathrm{~h}$, respectively (from top panel to bottom panel) over a $145 \mathrm{~km} \times 145 \mathrm{~km}$ grid with $1 \mathrm{~km} \times 1 \mathrm{~km}$ resolution. The figures show precipitation sums. The plusses are rain gauges and the dashed box delineates the $100 \mathrm{~km} \times 100 \mathrm{~km}$ simulation domain. 

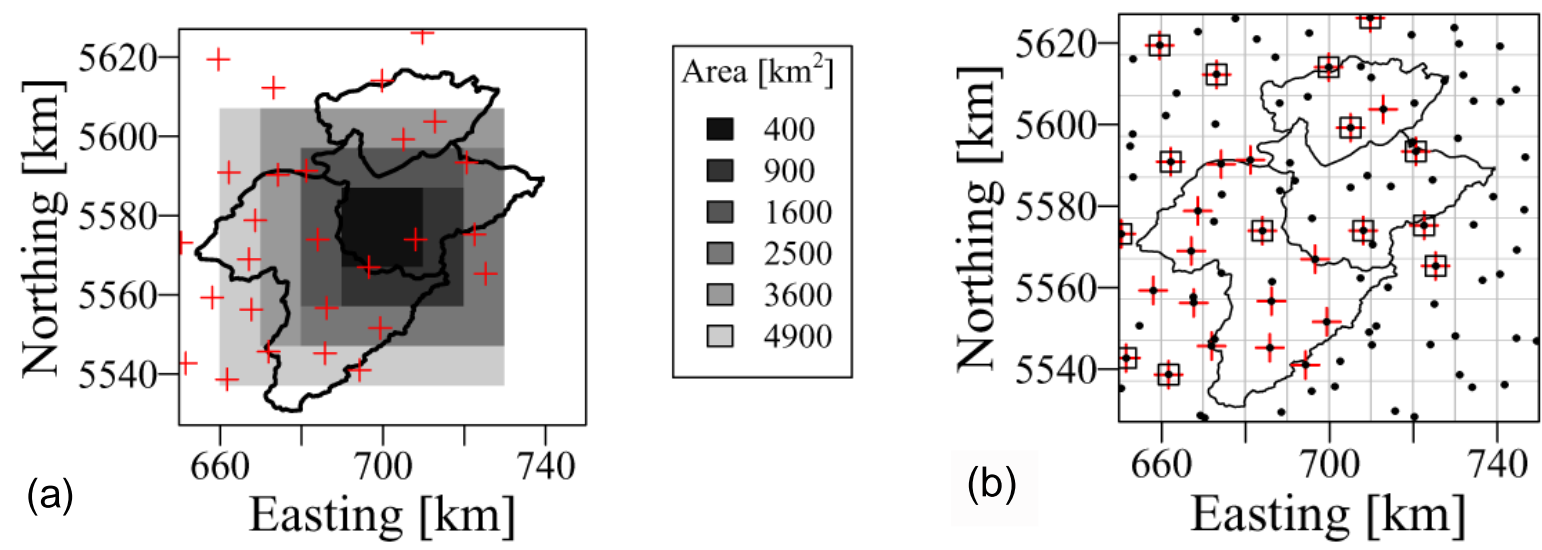

Fig. 6. (a) Six nested "sub-catchments" with increasing catchment areas. Rain gauges are indicated by plusses. (b) Three types of rain gauge densities: dots $(N=100)$, red pluses $(N=27)$ and squares $(N=14)$. Extent of figure corresponds to the black dashed box in Fig. 5 and the grey lines show the $10 \mathrm{~km} \times 10 \mathrm{~km}$ grid resolution.

These aspects are considered as follows. Initially, the synthetic circular-shaped rainfall cell with constant intensity is advected over the catchment at five different advection speeds. The three types of rain gauge densities are used to sample the synthetic rainfall. Then, these synthetic point observations are employed in the simulations of the spatial rainfall fields. Both temporal and spatial correlations, which need to be taken into account, are expressed by the variogram models. Finally, the generated rainfall fields are analysed for different simulation memories and catchment sizes. By carrying out such a sensitivity analysis of a very simplistic rainfall cell with known spatial statistics, constant rainfall intensity and known advection speed, we are able to eliminate several sources of uncertainty which would arise with the realworld data. The purpose of this sensitivity analysis is to obtain a better understanding of the spatial and temporal scales involved in the rainfall-runoff transformation before turning to the real-world case.

Because of the higher computational costs of the timedependent multivariate conditional simulations at high resolution grids, the simulation domain is reduced for that purpose to $100 \mathrm{~km} \times 100 \mathrm{~km}$ with a $10 \mathrm{~km} \times 10 \mathrm{~km}$ raster resolution (dashed box in Fig. 5). The analysis includes 24 ensemble realisations and the length of the rainy periods varies between 4 and $18 \mathrm{~h}$, depending on the advection speed.

\subsubsection{Conditional simulations: real-world experiment}

Finally, the real-world experiment will focus on the three events described by Hazenberg et al. (2011) (see Sect. 2.1). For these events, the impact of time and area as described in Sect. 2.5.2 are analysed using the actual observation network (27 rain gauges). Moreover, to verify the accuracy of the method at unobserved locations, cross-validation is carried out by thinning the observation network with $50 \%$.

\section{Results}

\subsection{Interpretation of direct and cross variograms}

Empirical and modelled spherical direct and crossvariograms (Sect. 2.2) are calculated for two cases of a synthetic circular-shaped rainfall event with an intensity of $2 \mathrm{~mm} \mathrm{~h}^{-1}$. The first case consists of two rain fields (see 1 and 2 in Fig. 7), which are complementary. The second case consists of four advected rainfall fields (Fig. 7, right panel). The intersection of the third and the fourth rainfall field (Fig. 7, right panel) yields exactly half of the rainfall area. Since the third and the fifth rainfall fields are tangent, the intersection of the fourth and the fifth rainfall field covers around $28 \%$ of the rainfall area (Glassner, 1998). Moreover, the intersection of the fifth and the sixth rainfall field yields again exactly half of the rainfall area. We chose a rather small circular-shaped rainfall cell with a $36 \mathrm{~km}$ diameter, to minimise the impact of boundary effects.

Figure $8 \mathrm{a}$ and $\mathrm{b}$ show the direct and cross-variograms of the two complementary rainfall fields in Fig. 7 (left and middle panels). These have been square-root transformed, for the two sampling densities: a dense synthetic network (21 025 points covering all raster pixels) and the real world network (42 rain gauges). We can observe that the two direct variograms are identical and symmetrical with respect to their cross-variogram. This holds for both sampling densities. As expected, the real-world rain gauge network has a larger sill and a larger scatter in the empirical variograms than the much denser synthetic observation network.

For the advected cell of Fig. 7 (right panel), the direct and cross-variograms are shown in Fig. 8c and d. For a decreasing intersected area between the two rainfall fields, the fitted spherical sills decrease proportionally using the dense synthetic network (Table 2). Zero overlapping area (i.e., three combinations: rainfall fields 3 and 5, 3 and 6, 4 and 6), 

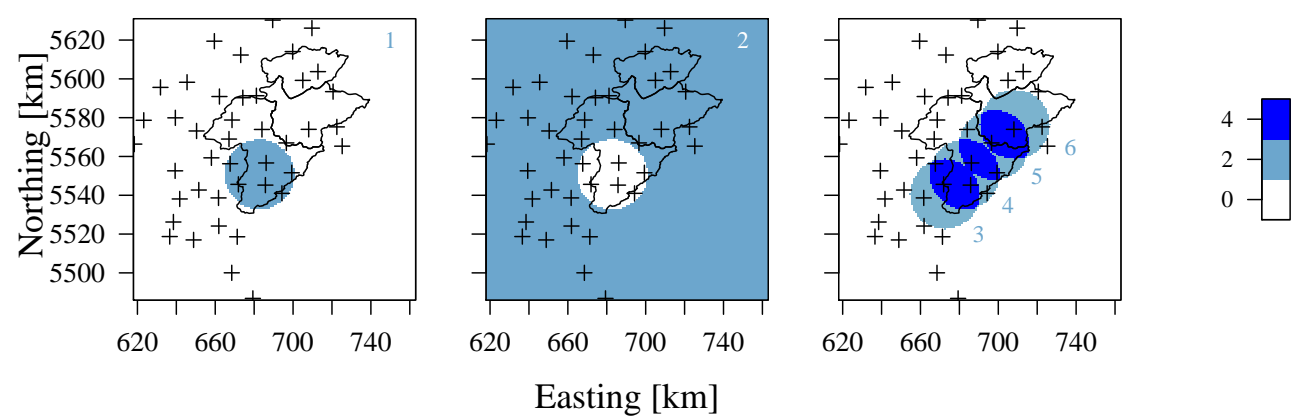

Fig. 7. Sensitivity analysis. Circular-shaped rainfall events consisting of six rainfall fields $1-6$. Raster resolution is $1 \mathrm{~km} \times 1 \mathrm{~km}$. Plusses show the rain gauges and black line delineates the Upper Ourthe, Amblève and Vesdre catchments.

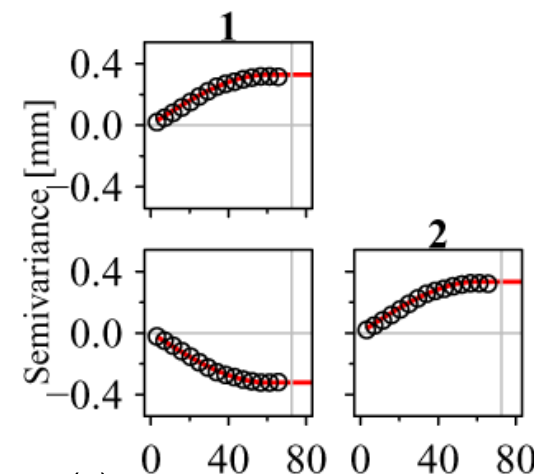

(a)
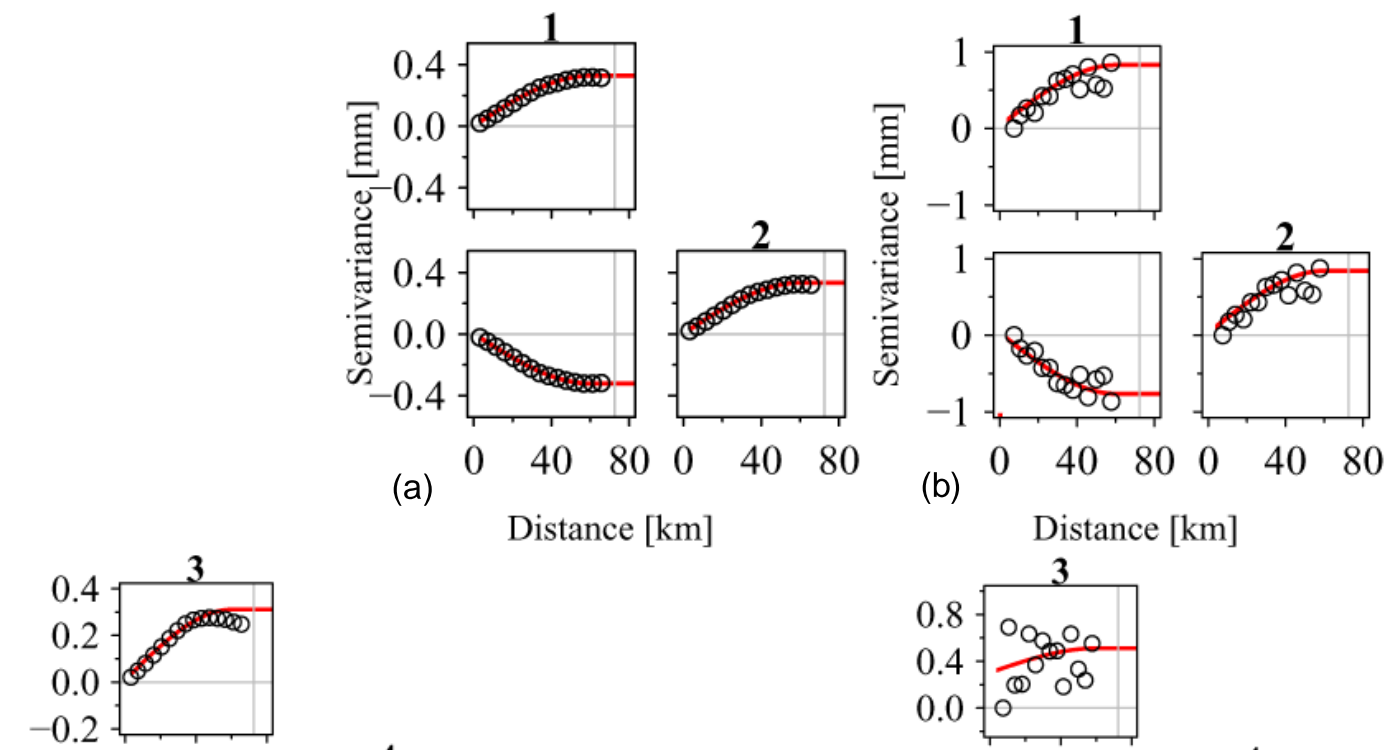

Distance $[\mathrm{km}]$

(b)

Distance [km]
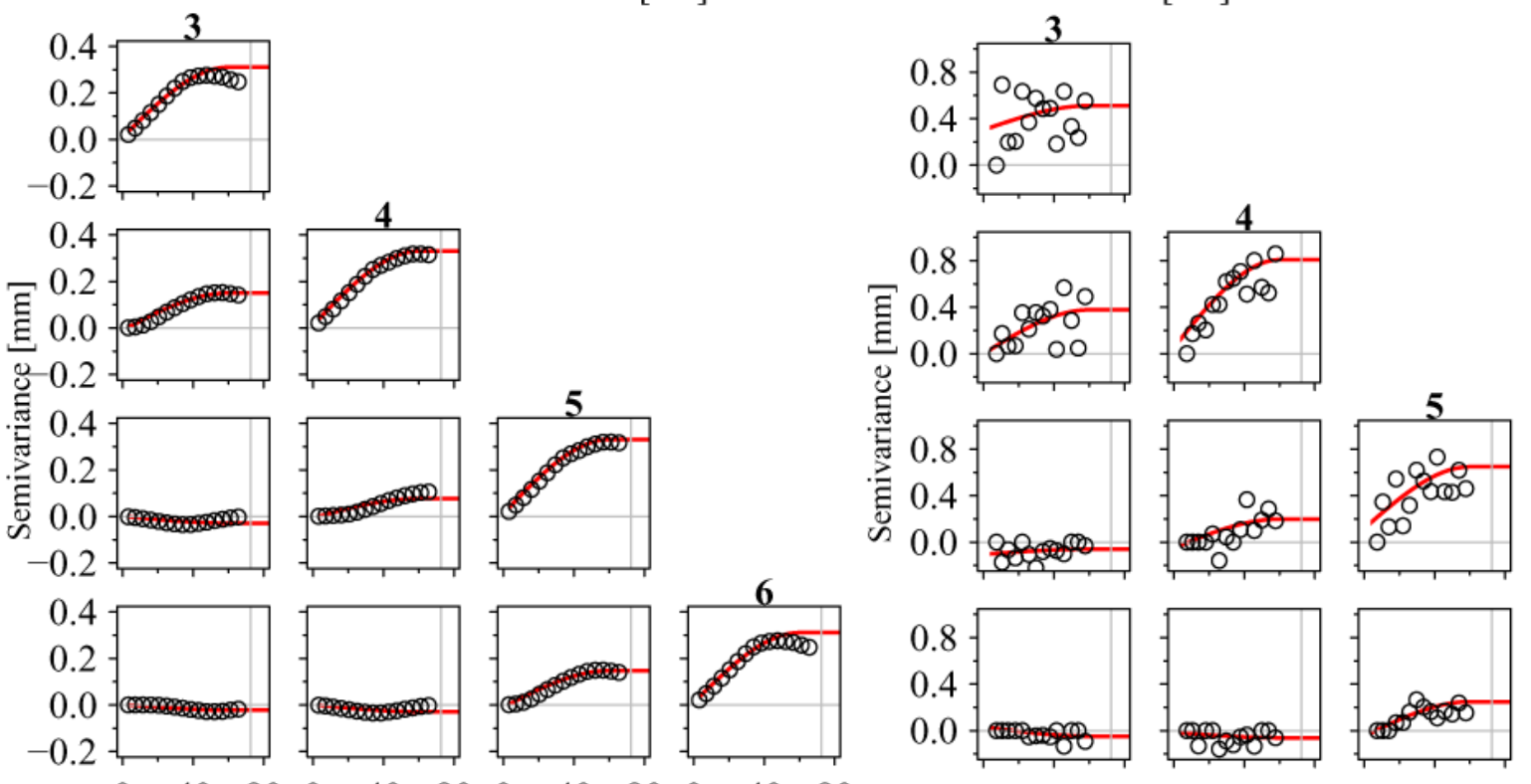

6

(c)

$0 \quad 40 \quad 80$

Distance [km]

Distance [km]

Fig. 8. Sensitivity analysis. Direct and cross-variograms for rainfall fields 1 and 2 (Fig. 7) derived from all grid points (a) and only the rain gauge grid points (b). Direct and cross-variograms for rainfall fields 3-6 (Fig. 7) derived from all the grid points (c) and only the rain gauge grid points (d). Grey vertical line shows the range corresponding to twice the diameter of the rainfall circle. 
Table 2. Sensitivity analysis. Fitted sills ( $\mathrm{mm}$ ) using the spherical model for direct and cross-variograms for rainfall fields 3-6 (see Fig. 7) derived for the dense synthetic observation network (Fig. 8c).

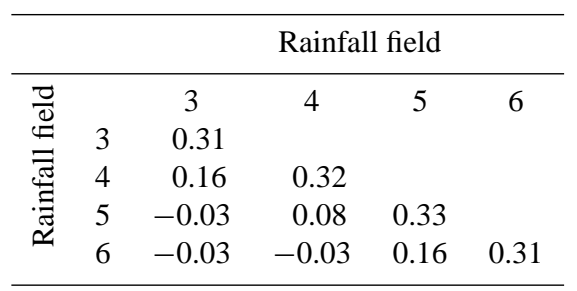

gives a sill of about zero. For the real-world network similar behaviour can be observed, although the scatter in the fitted models through the empirical variograms is much larger. Note that even though the circular-shaped rainfall cell is identical for all rainfall fields, the shape of the empirical variograms differs from each other, because the rain gauge configuration is not spatially uniform and effectively changes for each rainfall field.

\subsection{Conditional simulations: sensitivity analysis}

As a first example, the impact of advection speed and the number of hours used as part of the conditional simulation was identified for the setup presented in Fig. 5. As such, precipitation is sampled by the real-world rain gauge network ( $N=27$ in Fig. 6), while a total of up to eight hours are used as part of the simulation memory $(0-7 \mathrm{~h})$. An example of such a simulation for one pixel is shown in Fig. 9. We can observe that for the time-independent univariate case (i.e., conditioned on $0 \mathrm{~h}$ of previously simulated fields), there is no consistency for ensemble realisations over time, since no information between individual time steps is taken into account. However, for the time-dependent multivariate cases (i.e., conditioned on 1-7 h of previously simulated fields), the temporal consistency for ensemble realisations becomes more clear. Overall, the spread in simulated precipitation increases when a larger number of previously simulated fields is included as part of the simulations.

From the event-based perspective (see bold line in Fig. 4), the scatter plots between the simulated mean precipitation over time $\left(\hat{\mu}_{T, j}\right)$ and the corresponding standard deviation $\left(\hat{\sigma}_{T, j}\right)$ for the first four ensemble realisations are shown in Fig. 10 separately, where $\hat{\mu}_{T, j}$ and $\hat{\sigma}_{T, j}$ are plotted for all the individual pixels within the $4900 \mathrm{~km}^{2}$ catchment (see Fig. 6b). The panels indicate that the spread in $\hat{\mu}_{T, j}$ gradually increases from the time-independent univariate conditional simulation to the most complex time-dependent multivariate scenario. This is in agreement with the simulation results shown in Fig. 9. Because we are not only interested in the mean simulated values, but also in their temporal variability, standard deviations are plotted against the corresponding means (Fig. 11). The slope of the fitted linear regres-

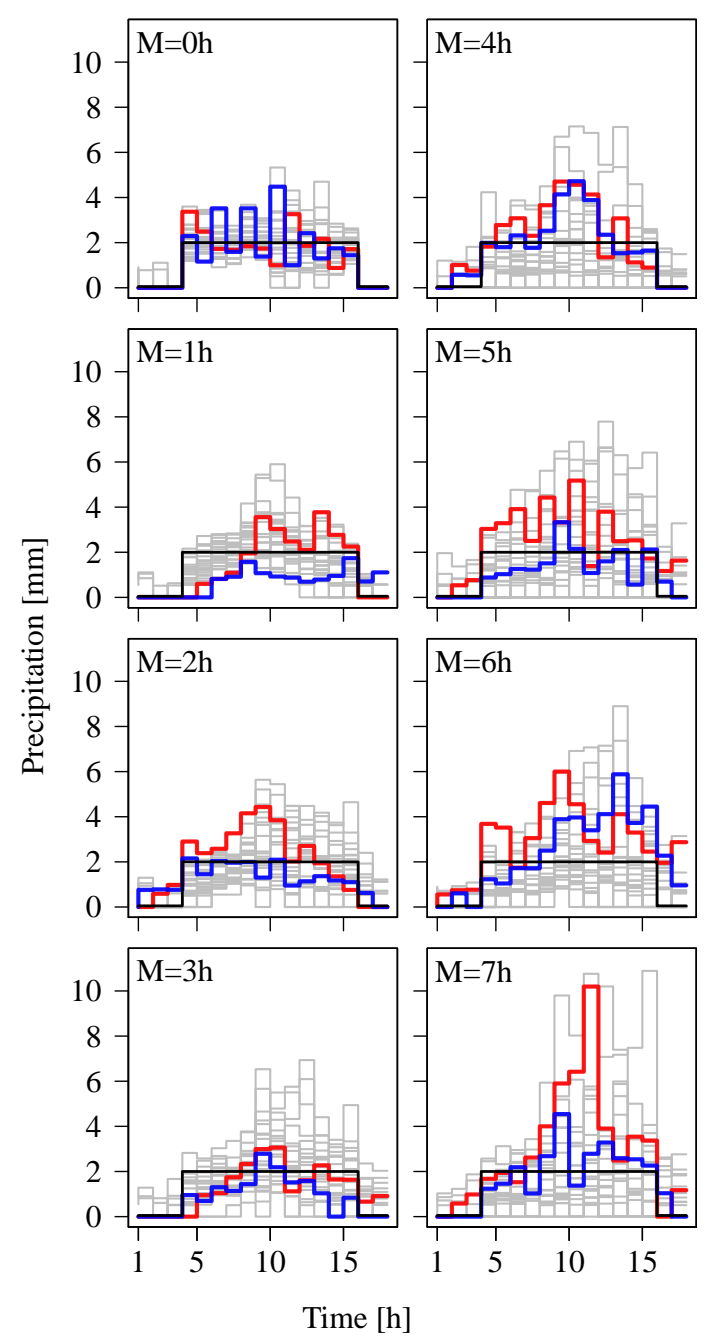

Fig. 9. Sensitivity analysis. Precipitation ensemble (24 realisations in grey, from which two realisations are shown in red and blue) for eight types of simulation scenarios given a simulation memory $M$ of $0-7 \mathrm{~h}$, for a pixel located in the centre of the simulation domain. Black line stands for the synthetic rain gauge observation. Rainfall scenario for the advection speed of $6 \mathrm{~km} \mathrm{~h}^{-1}$ (see Fig. 5).

sion line represents the mean temporal coefficient of variation. The coefficients of variation are gradually decreasing for longer simulation memories, which indicates lower temporal variability and larger temporal coherence for longer simulation memories.

For the across-ensemble perspective (see $\square$ in Fig. 4), the scatter plots between simulated mean precipitation acrossensemble $\left(\hat{\mu}_{J, t}\right)$ and their corresponding standard deviations $\left(\hat{\sigma}_{J, t}\right)$ for the four time steps $(t=7,8,9,10)$ are shown in Fig. 11, where $\hat{\mu}_{J, t}$ and $\hat{\sigma}_{J, t}$ are plotted for all individual pixels within the $4900 \mathrm{~km}^{2}$ catchment. The figures reflect a rather constant spread in $\hat{\mu}_{J, t}$ for all simulation memories during those four time steps. Nevertheless, the fitted coefficients of variation are gradually increasing for longer 


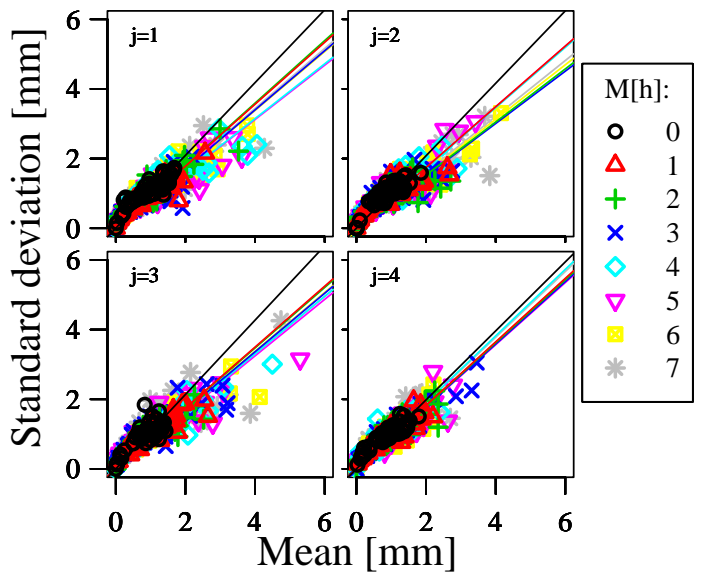

Fig. 10. Sensitivity analysis. Scatter plot of $\hat{\mu}_{T, j}$ and $\hat{\sigma}_{T, j}$ with fitted coefficients of variations $\left(\mathrm{CV}_{T}\right)$ for four ensemble realisations, an advection speed of $6 \mathrm{~km} \mathrm{~h}^{-1}$ and a catchment area of $4900 \mathrm{~km}^{2}$. Different points in each panel are for individual points (pixels) of the catchment.

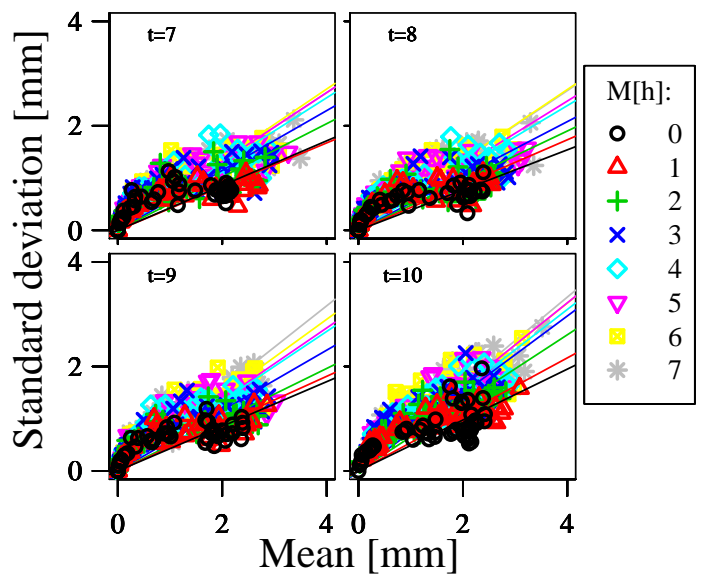

Fig. 11. Sensitivity analysis. Scatter plot of $\hat{\mu}_{J, t}$ and $\hat{\sigma}_{J, t}$ with fitted coefficients of variations $\left(\mathrm{CV}_{J}\right)$ for four time steps, an advection speed of $6 \mathrm{~km} \mathrm{~h}^{-1}$ and a catchment area of $4900 \mathrm{~km}^{2}$. Different points in each panel are for individual points (pixels) of the catchment.

simulation memories. This is in line with the higher ensemble spread for longer simulation memories (see Fig. 9).

Since the purpose of this paper is to assess the impact of precipitation uncertainty estimation across the ensemble (i.e., $\hat{\mu}_{J, t}$ vs. $\hat{\sigma}_{J, t}$ ), which is of key interest especially for hydrological data assimilation applications, the next step is to evaluate it in a lumped manner over all time steps. This was done by overlapping the individual sub-plots (partially depicted for $t=7,8,9,10$ in Fig. 11) for all time steps. An example is shown in Fig. 12, where the coefficients of variation increase with rainfall simulations conditioned on longer simulation memories.

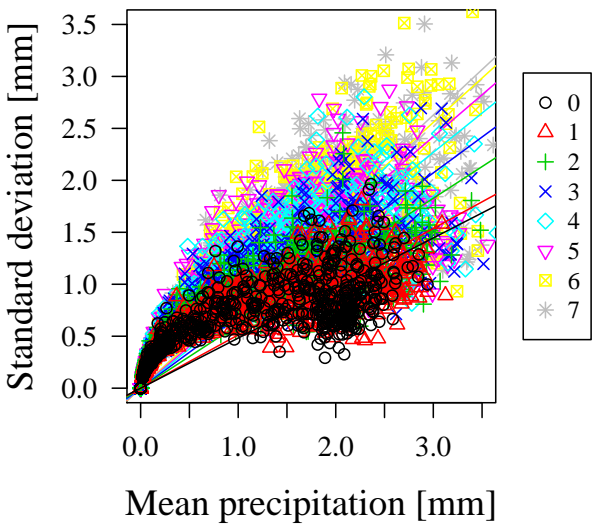

Fig. 12. Sensitivity analysis. Scatter plot $\hat{\mu}_{J, t}$ and $\hat{\sigma}_{J, t}$ lumped over time with fitted coefficients of variations $\left(\mathrm{CV}_{J}\right)$ for the rainfall scenario with an advection speed of $6 \mathrm{~km} \mathrm{~h}^{-1}$ (see Fig. 5) and a catchment area of $4900 \mathrm{~km}^{2}$. Different points in the panel are for individual points (pixels) of the catchment.

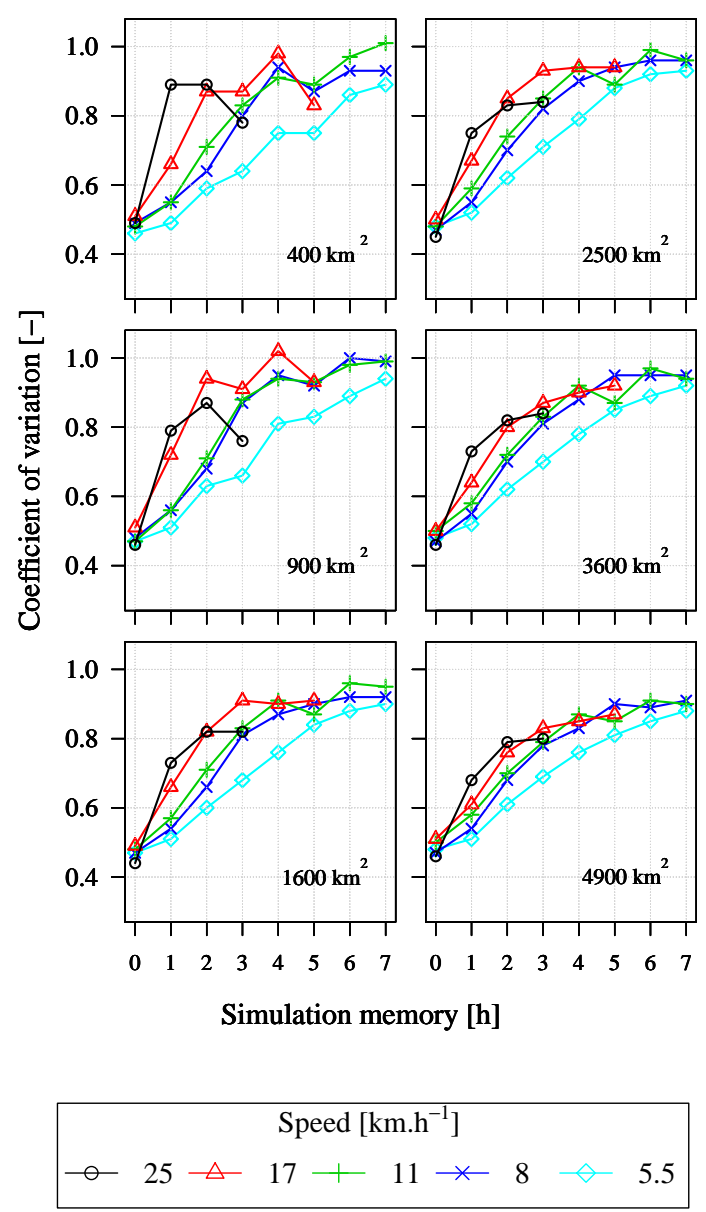

Fig. 13. Sensitivity analysis. Coefficient of variation $\left(\mathrm{CV}_{J}\right)$ for different catchment sizes and advection speeds. 
Table 3. Sensitivity analysis. Fitted y-intercept and horizontal asymptote values of coefficients of variation $\left(\mathrm{CV}_{J}\right.$, in Fig. 13) for different rain gauge networks (Fig. 6b).

\begin{tabular}{rrr}
\hline $\begin{array}{r}\text { Number } \\
\text { of gauges }\end{array}$ & y-intercept & $\begin{array}{r}\text { Horizontal } \\
\text { asymptote }\end{array}$ \\
\hline 14 & 0.5 & 1 \\
27 & 0.45 & 0.9 \\
100 & 0.4 & 0.7 \\
\hline
\end{tabular}

The behaviour of the coefficients of variation $\left(\mathrm{CV}_{J}\right)$ for individual catchment sizes, advection speeds and simulation memories is summarised in Fig. 13. We can observe that for a larger advection speed the coefficient of variation rises faster and approaches its upper level earlier than for slower moving systems. Note that for the faster events, with advection speeds of 25 and $17 \mathrm{~km} \mathrm{~h}^{-1}$ lasting four and six hours, respectively (Fig. 5), the coefficients of variation can be obtained only up to the three and five previously simulated hours. Additionally, the catchment size does not have a large influence on the coefficients of variation except for very small catchment sizes consisting of only few pixels, where the estimation is significantly affected by sampling uncertainty. Because small catchments are nested, most variability is smoothed out for larger catchments sizes.

The aforementioned examples were based on the realworld rain gauge network $(N=27)$. When the number of rain gauges is decreased to the half of its original density $(N=14)$, the general shape of the fitted spherical variogram through the estimated coefficients of variation remains very similar. However, both y-intercept and horizontal asymptote values become higher (Table 3 ). This indicates a slight increase in the across-ensemble variability. For a dense synthetic network $(N=100)$ the opposite occurs. Both the yintercept and horizontal asymptote values decrease, which means a lower across-ensemble variability. These results suggest that the method is rather robust. Additionally, the effect of thinning the observation network on the mean simulated error is provided in the following section, where the crossvalidation at unobserved locations is carried out for the realworld experiment.

\subsection{Conditional simulations: real-world experiment}

The real rain gauge observations have been analysed within the same conditional simulation framework as was done within the sensitivity analysis. The resulting coefficients of variation $\left(\mathrm{CV}_{J}\right)$ for the different catchment sizes and simulation memories are shown in Fig. 14. They correspond well with the sensitivity analysis. For the two fast-moving systems (22 October 2002 and 1 January 2003), there is a steep increase in the across-ensemble spread $\left(\mathrm{CV}_{J}\right)$, which becomes more or less steady after simulation memories of $1-2 \mathrm{~h}$. This means that no further uncertainty is added to sim-
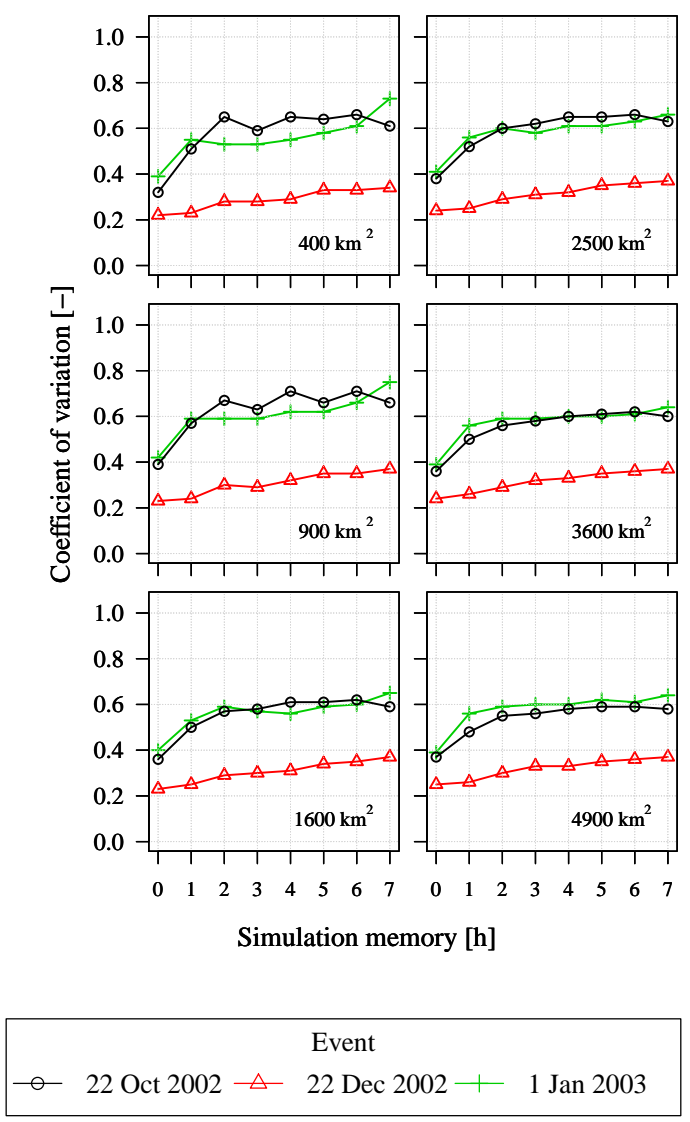

Fig. 14. Real-world experiment. Coefficient of variation $\left(\mathrm{CV}_{J}\right)$ for different catchment sizes and three rainfall events.

ulated precipitation fields by conditioning on more than two hours of previous simulations. For a large-scale stratiform system (22 December 2002) moving very slowly, a gentle rise in $\mathrm{CV}_{J}$ is observed. For this event, the horizontal asymptote is reached when a simulation memory of $>5 \mathrm{~h}$ is taken into account. Moreover, these values of $\mathrm{CV}_{J}$ are considerably smaller than for the faster systems.

To verify the accuracy of the presented method, crossvalidation was carried out in the terms of the mean error. The mean error is defined as the difference between the rain gauge observation and the corresponding across ensemble mean $\left(\hat{\mu}_{J, t}\right.$, Eq. 5). The rain gauge observations employed in the validation were independent from the data used for simulation. To simulate the precipitation fields, 14 rain gauges out of the complete observation network of 27 rain gauges were used (Fig. 6b). The remaining 13 rain gauges were kept for validation and their mean errors were calculated for all time steps and for all eight simulation memories (dashed histograms in Fig. 15). Additionally, we compared these validation mean errors with the simulation mean errors at the same 13 locations. These simulation mean errors were obtained by simulating precipitation fields using all 27 rain gauges (grey histograms in Fig. 15). Figure 15 shows that 
a)

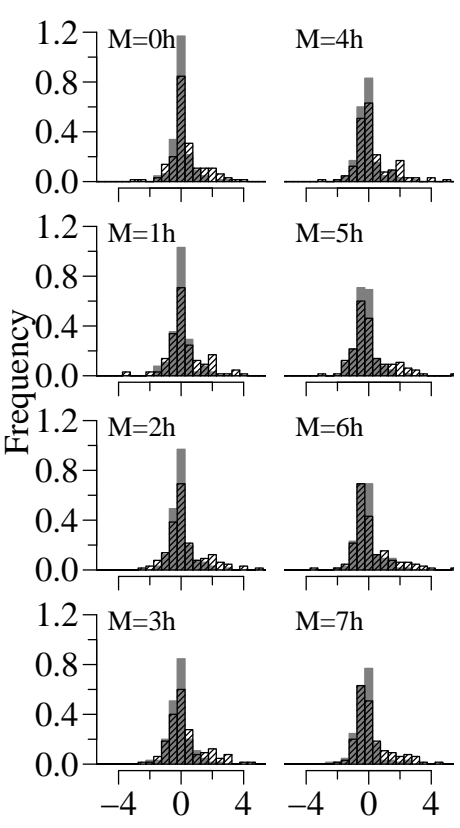

b)
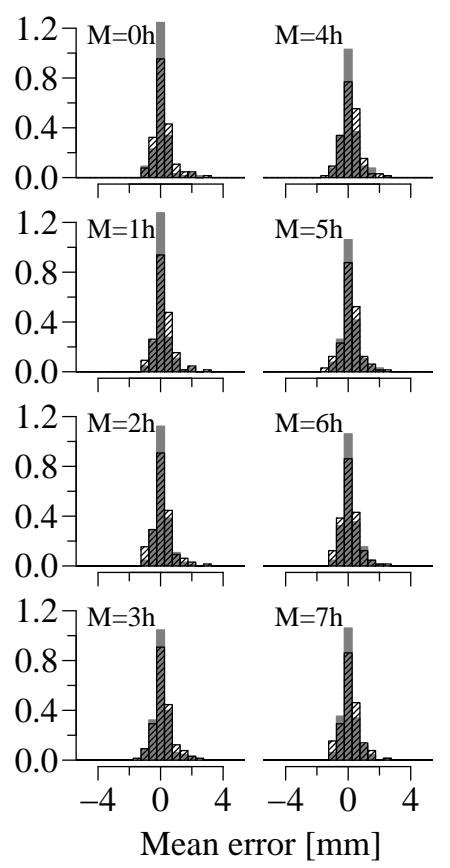

c)
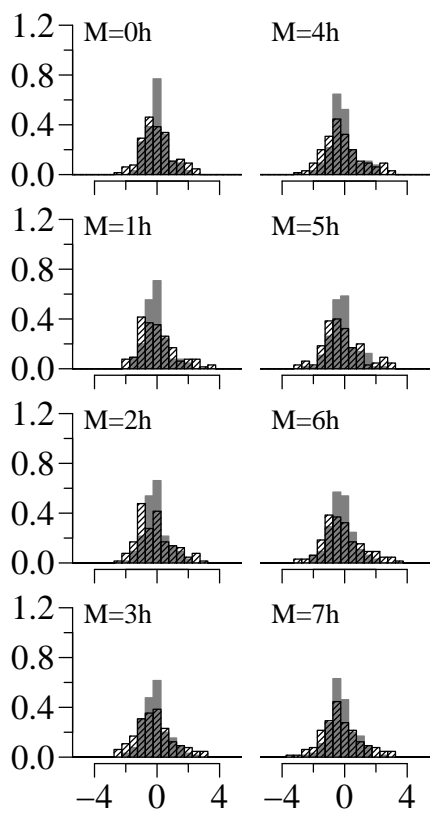

Fig. 15. Validation for three real-world events for simulation memories ranging from 0 to 7 h: (a) 22 October 2002 , (b) 22 December 2002 and (c) 1 January 2003. Histograms of the validation mean errors at 13 rain gauges (dashed histograms). Histograms of the simulation mean errors for the same 13 rain gauges (grey histograms).

the validation mean errors at the unobserved locations are unbiased and have a consistent behaviour over all simulation memories (dashed histograms in Fig.15). Furthermore, the histograms of the validation mean errors have smaller peaks than the mean errors of the simulated precipitation fields. This increase in uncertainty is to be expected, because in the validation only half of the rain gauge data are used to simulate spatial precipitation fields. Note that the spread in histograms agrees well with the corresponding standard deviations shown in Table 1.

\section{Synthesis and discussion}

The overall temporal correlation structure of the simulated precipitation field can be quantified using the first order autocorrelation coefficient $r_{1 \mathrm{~h}}$, which expresses the correlation of a precipitation time series for a time lag of $1 \mathrm{~h}$. Figure 16 shows box plots of $r_{1 \mathrm{~h}}$ for time series of areal precipitation for different catchment sizes and simulation memories. For a robust investigation of the autocorrelation, it is preferable to have long time series. Therefore, we decided to use the data for the slowest synthetic event with a duration of $18 \mathrm{~h}$ (see Fig. 5). It can be observed that $r_{1 \mathrm{~h}}$ increases when moving from time-independent univariate $(M=0)$ to the timedependent multivariate conditional simulations $(M=1-7 \mathrm{~h})$. Nevertheless, the major difference between the univariate simulations (grey boxplots in Fig. 16) and the multivariate simulations (white boxplots in Fig. 16) decreases for larger catchments. This is a direct result of the relatively small size of the rain cell with respect to the catchment area.

The across-ensemble uncertainty was quantified using the lumped $\mathrm{CV}_{J}$, and its shape for both the sensitivity analysis (Fig. 13) as well as the real-world experiment (Fig. 14) clearly resembles the shape of the spherical variogram (Eq. 2). By fitting the spherical model, the range can be obtained, which represents a simulation memory threshold of the system, after which no additional precipitation uncertainty is added by including more previous information. The fitting of the range is done using the gstat $R$ package (Pebesma, 2004) and is an analogy to the method explained in Sect. 2.2.

For the sensitivity analysis, this leads to a nonlinear relation between the advection speed and its corresponding fitted range [h] (Fig. 17):

Range $\times$ Speed $\approx 50 \mathrm{~km}$.

This result indicates that for typical advection speeds $\left(>20 \mathrm{~km} \mathrm{~h}^{-1}\right)$ no uncertainty in terms of across-ensemble spread is added to the simulated precipitation fields by conditioning it on more than two previous hourly simulations.

We need to bear in mind, however, that the synthetic case analysed here is the most simplistic example of a precipitation cell, which assumes a known and constant advection 


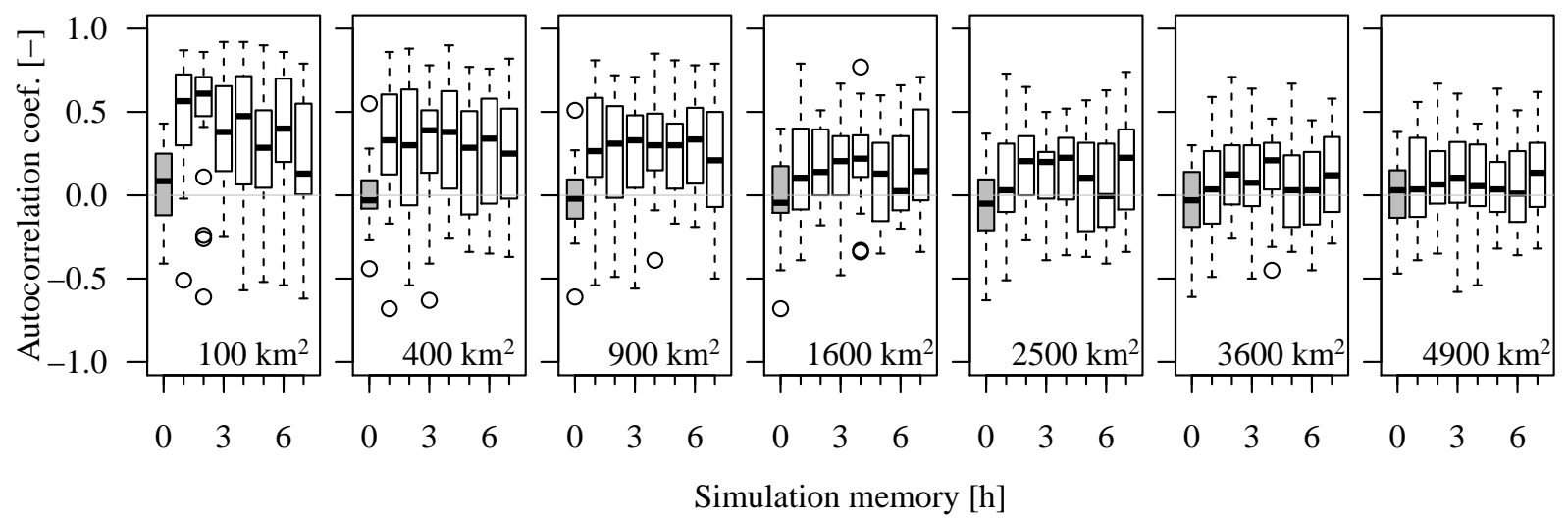

Fig. 16. Sensitivity analysis. Boxplots of the first-order autocorrelation coefficients ( 24 realisations) for the time series of the catchment's areal precipitation for different catchment sizes and simulation memories (time-independent univariate simulation in grey, time-dependent multivariate simulations in blank), rainfall scenario with an advection speed of $6 \mathrm{~km} \mathrm{~h}^{-1}$ and duration of $18 \mathrm{~h}$ (see Fig. 5).

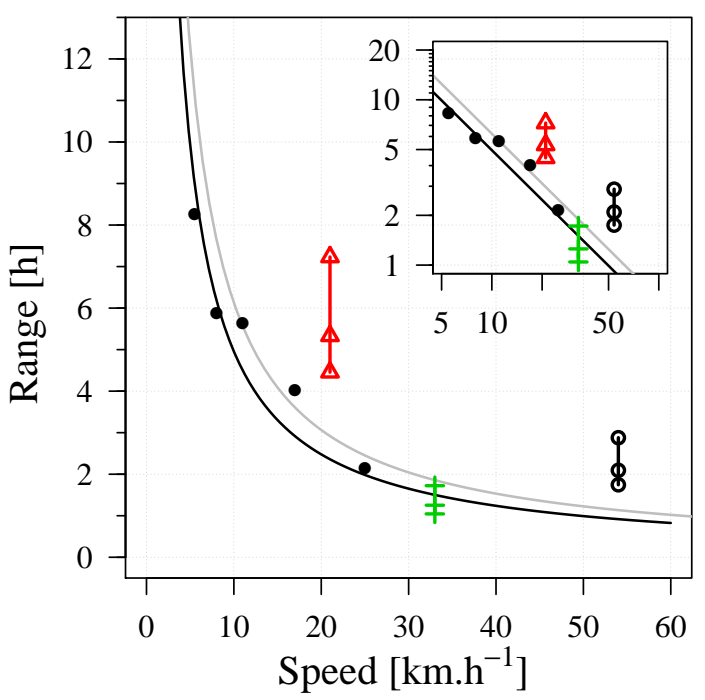

Fig. 17. Nonlinear relation between the advection speed and the threshold range for a catchment area of $4900 \mathrm{~km}^{2}$. Black filled circles represent five synthetic circular-shaped rainfall cells. Black line delineates Eq. (10). Black open circle, red triangle and green plus show three real-world rainfall events (see Fig. 14) with the values of the ranges for $100 \%, 90 \%$ and $80 \%$ (from top to bottom) of the corresponding partial sills. Grey line delineates the fitted nonlinear relation for synthetic rainfall cells with double diameter. The identical figure with logarithmic axes is given in the inset.

speed, has a rather small dimension, and results in a constant rainfall intensity. For real-world examples, on the other hand, a much higher spatial and temporal variability in the dynamics of precipitation systems can be expected. This means that the effective ranges of previous information are expected to increase. This corresponds well with the results obtained for the real-world experiment, which are shown in Fig. 17. To quantify the apparent uncertainty in the fitted ranges for the three real rainfall events, the values of the ranges for $80 \%$,
$90 \%$ and $100 \%$ of the partial sills are shown. For the largescale stratiform system (red triangles), the fitted ranges vary around $5-7 \mathrm{~h}$, which is considerably longer than for the two faster systems. This can be caused by the combination of (1) the gentle increase and in general lower values of coefficient of variation, which are about half of the values for the two remaining events (recall Fig. 14) and (2) the size of the observed precipitation system, which for the real-world case has a larger dimension. Because of this latter property, we repeated the sensitivity analysis for rainfall cells with twice the original diameter size, which made its area four times larger. For these cases, indeed a larger coefficient of $63 \mathrm{~km}$ is obtained (grey line in Fig. 17). Finally, when we refer back to Fig. 2, which shows the exponential decay of the autocorrelation of the areal precipitation estimates, we can conclude that considering a simulation memory of about two to three hours is relevant for the presented stratiform winter rainfall events.

Overall, for the time-dependent multivariate conditional simulations with longer simulation memories, we observed a larger across-ensemble spread. The commonly defined time-independent rainfall perturbations used for the hydrological data assimilation applications have noise errors with a standard deviation up to $50 \%$ of the observed precipitation (e.g. Pauwels and De Lannoy, 2006; Weerts and El Serafy, 2006). This corresponds well with our simulations, in which the maximum slope of the fitted coefficients of variation is about 0.5 (Fig. 11). However, in comparison with the aforementioned references, we were able to additionally capture the temporal coherence for each realisation in space.

Moreover, conditional simulation methods increase computational costs quite dramatically in comparison with interpolation methods. Fortunately, this problem can be partly circumvented by decreasing the temporal $(\Delta t[\mathrm{~min}])$ or spatial $(\Delta r[\mathrm{~km}])$ resolution of the simulation model. From an applied hydrological point of view, an hourly time step is usually recommended for regions with an area of $\sim 10000 \mathrm{~km}^{2}$ 
(Berne et al., 2004). Moreover, the choice for a rather coarse $10 \mathrm{~km} \times 10 \mathrm{~km}$ grid resolution, as was chosen in this study, can be supported by the analysis carried out by Berne et al. (2004), who reported the spatial rainfall resolution to be $4.5 \sqrt{\Delta t}$, which yields a decorrelation distance of about $35 \mathrm{~km}$ for $\Delta t=60 \mathrm{~min}$.

A limiting factor of this study can be that the spatial anisotropy of the rainfall field as well as the local topography were not considered. Additionally, we did not use other sources of precipitation measurements, such as weather radar. Therefore, obtaining precipitation ensembles from radar remains an important continuation of this study. The main benefit of using radar is that one obtains much more information on the spatial characteristics of both the precipitation field and type (Hazenberg et al., 2011). It is then possible to take two different approaches: (1) the rain gauge perspective, where we imagine that that the weather radar data is only used to provide information on where it rains and which gauges are specifically to be used to generate a variogram (since they belong to the same region), (2) the radar perspective, where the gauges are used to correct the radar for any remaining bias, while the uncertainty in the precipitation field is obtained from the volumetric radar information. We will present some ideas on these issues and approaches related to these issues in future publications.

\section{Summary and conclusions}

In this paper, a rain gauge precipitation ensemble generator at hourly time step using time-dependent multivariate conditional simulations, which were made conditional on previous simulations back in time was developed. As such, a plausible way to generate temporal correlation structures for precipitation for each realisation over time was introduced. Next, we identified the uncertainty and the temporal correlation structures in the simulated fields based on (1) the number of previous simulation hours on which the new simulation is conditioned, (2) the advection speed of the rainfall event, (3) the size of the catchment considered and (4) the rain gauge density within the catchment.

The sensitivity analysis shows that for typical advection speeds of $>20 \mathrm{~km} \mathrm{~h}^{-1}$ no uncertainty in terms of acrossensemble spread lumped over time (expressed using the coefficient of variation) is added to simulated precipitation fields by conditioning them on more than one or two previous hourly simulations. In the real-world experiment, which exhibits a larger spatial and temporal variability, the timedependent simulations require somewhat longer simulation memories. Additionally, by halving the observation network, i.e., using 14 rain gauges, the uncertainty in the sensitivity analysis increases only slightly. Furthermore, the crossvalidation shows that the simulations at unobserved locations are unbiased and have a consistent behaviour over all simulation memories. Finally, the first-order autocorrelation coefficient indicated the presence of temporal coherence in the time series of the areal precipitation using the timedependent multivariate conditional simulation in comparison with the time-independent univariate conditional simulations. Nevertheless, this coherence was found to decrease with increased catchment area.

The presented technique to generate spatial precipitation ensembles can be easily implemented within a hydrological data assimilation framework to be used as an improvement over currently used simplistic approaches to perturb the interpolated point or spatially distributed estimates (as referred to in the introduction). As shown, using the timedependent rainfall simulations with at least one hour of simulation memory, but preferably longer, we were able to reach this goal and obtain precipitation ensembles with temporal correlation structures that are plausible from a hydrometeorological perspective. Therefore, the corresponding simulated spatially distributed model states produced by that rainfall ensemble should inherit this temporal aspect. The advantage of having the temporal coherence in model states is that it eliminates the need to smooth possible extreme state values, which can be the case when neglecting it. A hydrological application of the presented spatial precipitation ensemble generator is presented by Rakovec et al. (2012).

Acknowledgements. We thank the Hydrological Service of the Walloon Region of Belgium (MET-SETHY) and the Royal Meteorological Institute of Belgium (KMI) for providing the hydrological and meteorological data. This research is financially supported by the Flood Control 2015 programme (www.floodcontrol2015.nl) and the EU-FP7 Project IMPRINTS (FP7-ENV-2008-1-226555). This support is gratefully acknowledged. The authors would also like to thank M. van den Berg, two anonymous reviewers and the editor for their constructive comments, which improved the quality of the manuscript.

Edited by: Y. Liu

\section{References}

AghaKouchak, A., Bardossy, A., and Habib, E.: Conditional simulation of remotely sensed rainfall fields using a nonGaussian v-transformed copula, Adv. Water Resour., 33, 624634, doi:10.1016/j.advwatres.2010.02.010, 2010.

Berne, A., Delrieu, G., Creutin, J.-D., and Obled, C.: Temporal and spatial resolution of rainfall measurements required for urban hydrology, J. Hydrol., 299, 166-179, doi:10.1016/j.jhydrol.2004.08.002, 2004.

Berne, A., ten Heggeler, M., Uijlenhoet, R., Delobbe, L., Dierickx, Ph., and de Wit, M.: A preliminary investigation of radar rainfall estimation in the Ardennes region and a first hydrological application for the Ourthe catchment, Nat. Hazards Earth Syst. Sci., 5, 267-274, doi:10.5194/nhess-5-267-2005, 2005.

Beven, K.: Rainfall-runoff modelling: the primer, John Wiley \& Sons, 2001. 
Bivand, R. S., Pebesma, E. J., and Gómez-Rubio, V.: Applied spatial data analysis with R, Springer, 2008.

Brauer, C. C., Teuling, A. J., Overeem, A., van der Velde, Y., Hazenberg, P., Warmerdam, P. M. M., and Uijlenhoet, R.: Anatomy of extraordinary rainfall and flash flood in a Dutch lowland catchment, Hydrol. Earth Syst. Sci., 15, 1991-2005, doi:10.5194/hess15-1991-2011, 2011.

Ciach, G. and Krajewski, W.: Analysis and modeling of spatial correlation structure in small-scale rainfall in Central Oklahoma, Adv. Water Resour., 29, 1450-1463, doi:10.1016/j.advwatres.2005.11.003, 2006.

Clark, M. P. and Slater, A. G.: Probabilistic quantitative precipitation estimation in complex terrain, J. Hydrometeorol., 7, 3-22, doi:10.1175/JHM474.1, 2006.

Clark, M. P., Rupp, D. E., Woods, R. A., Zheng, X., Ibbitt, R. P., Slater, A. G., Schmidt, J., and Uddstrom, M. J.: Hydrological data assimilation with the ensemble Kalman filter: Use of streamflow observations to update states in a distributed hydrological model, Adv. Water Resour., 31, 13091324, doi:10.1016/j.advwatres.2008.06.005, 2008.

Cole, S. J. and Moore, R. J.: Distributed hydrological modelling using weather radar in gauged and ungauged basins, Adv. Water Resour., 32, 1107-1120, 2009.

Driessen, T. L. A., Hurkmans, R. T. W. L., Terink, W., Hazenberg, P., Torfs, P. J. J. F., and Uijlenhoet, R.: The hydrological response of the Ourthe catchment to climate change as modelled by the HBV model, Hydrol. Earth Syst. Sci., 14, 651-665, doi:10.5194/hess-14-651-2010, 2010.

Germann, U., Berenguer, M., Sempere-Torres, D., and Zappa, M.: REAL - Ensemble radar precipitation estimation for hydrology in a mountainous region, Q. J. R. Meteorol. Soc., 135, 445-456, doi:10.1002/qj.375, 2009.

Glassner, A. S. (Ed.): Graphics gems, Elsevier, 1998.

Goovaerts, P.: Geostatistics for Natural Resources Evaluation, Applied geostatistics series, Oxford University Press, 1997.

Goudenhoofdt, E. and Delobbe, L.: Evaluation of radar-gauge merging methods for quantitative precipitation estimates, Hydrol. Earth Syst. Sci., 13, 195-203, doi:10.5194/hess-13-1952009, 2009.

Grimes, D. I. F. and Pardo-Iguzquiza, E.: Geostatistical analysis of rainfall, Geogr. Anal., 42, 136-160, doi:10.1111/j.15384632.2010.00787.x, 2010.

Hazenberg, P., Leijnse, H., and Uijlenhoet, R.: Radar rainfall estimation of stratiform winter precipitation in the Belgian Ardennes, Water Resour. Res., 47, W02507, doi:10.1029/2010WR009068, 2011.

Kirstetter, P.-E., Delrieu, G., Boudevillain, B., and Obled, C.: Toward an error model for radar quantitative precipitation estimation in the Cévennes-Vivarais region, France, J. Hydrol., 394, 28 41, doi:10.1016/j.jhydrol.2010.01.009, 2010.

Krajewski, W. F. and Smith, J. A.: Radar hydrology: rainfall estimation, Adv. Water Resour., 25, 1387-1394, doi:10.1016/S03091708(02)00062-3, 2002.

Liu, Y., Weerts, A. H., Clark, M., Hendricks Franssen, H.-J., Kumar, S., Moradkhani, H., Seo, D.-J., Schwanenberg, D., Smith, P., van Dijk, A. I. J. M., van Velzen, N., He, M., Lee, H., Noh, S. J., Rakovec, O., and Restrepo, P.: Advancing data assimilation in operational hydrologic forecasting: progresses, challenges, and emerging opportunities, Hydrol. Earth Syst. Sci. Discuss., 9,
3415-3472, doi:10.5194/hessd-9-3415-2012, 2012.

Mandapaka, P., Villarini, G., Seo, B.-C., and Krajewski, W.: Effect of radar-rainfall uncertainties on the spatial characterization of rainfall events, J. Geophys. Res. Atmos., 115, D17110, doi:10.1029/2009JD013366, 2010.

Pauwels, V. R. N. and De Lannoy, G. J. M.: Improvement of modeled soil wetness conditions and turbulent fluxes through the assimilation of observed discharge, J. Hydrometeorol., 7, 458-477, doi:10.1175/JHM490.1, 2006.

Pebesma, E. J.: Multivariable geostatistics in $\mathrm{S}$ : the gstat package, Comput. Geosci., 30, 683-691, doi:10.1016/j.cageo.2004.03.012, 2004.

R Development Core Team: R: A Language and Environment for Statistical Computing, available at: http://www.R-project.org (last access: 7 December 2011), 2011.

Rakovec, O., Weerts, A. H., Hazenberg, P., Torfs, P. J. J. F., and Uijlenhoet, R.: State updating of a distributed hydrological model with Ensemble Kalman Filtering: effects of updating frequency and observation network density on forecast accuracy, Hydrol. Earth Syst. Sci., 16, 3435-3449, doi:10.5194/hess-163435-2012, 2012.

Renard, B., Kavetski, D., Leblois, E., Thyer, M., Kuczera, G., and Franks, S. W.: Toward a reliable decomposition of predictive uncertainty in hydrological modeling: Characterizing rainfall errors using conditional simulation, Water Resour. Res., 47, W11516, doi:10.1029/2011WR010643, 2011.

Rossiter, D.: Technical Note: Co-kriging with the gstat package of the $\mathrm{R}$ environment for statistical computing, Version 2.1, Self-published online, available at: http://www.itc.nl/personal/ rossiter/teach/R/R_ck.pdf (last access: 1 February 2012), 2007.

Schuurmans, J. M.: Hydrological now- and forecasting, Ph.D. thesis, Utrecht University, The Netherlands, 2008.

Schuurmans, J. M. and Bierkens, M. F. P.: Effect of spatial distribution of daily rainfall on interior catchment response of a distributed hydrological model, Hydrol. Earth Syst. Sci., 11, 677693, doi:10.5194/hess-11-677-2007, 2007.

Schuurmans, J. M., Bierkens, M. F. P., Pebesma, E. J., and Uijlenhoet, R.: Automatic prediction of high-resolution daily rainfall fields for multiple extents: The potential of operational radar, J. Hydrometeorol., 8, 1204-1224, doi:10.1175/2007JHM792.1, 2007.

Seo, D.-J. and Breidenbach, J.: Real-time correction of spatially nonuniform bias in radar rainfall data using rain gauge measurements, J. Hydrometeorol., 3, 93-111, doi:10.1175/15257541(2002)003;0093:RTCOSN $; 2.0 . C O ; 2,2002$.

Seo, D.-J., Breidenbach, J., and Johnson, E.: Real-time estimation of mean field bias in radar rainfall data, J. Hydrol., 223, 131-147, doi:10.1016/S0022-1694(99)00106-7, 1999.

Steiner, M., Smith, J., Burges, S., Alonso, C., and Darden, R.: Effect of bias adjustment and rain gauge data quality control on radar rainfall estimation, Water Resour. Res., 35, 2487-2503, 1999.

van de Beek, C. Z., Leijnse, H., Torfs, P. J. J. F., and Uijlenhoet, R.: Climatology of daily rainfall semi-variance in The Netherlands, Hydrol. Earth Syst. Sci., 15, 171-183, doi:10.5194/hess-15-1712011, 2011.

Verworn, A. and Haberlandt, U.: Spatial interpolation of hourly rainfall - effect of additional information, variogram inference and storm properties, Hydrol. Earth Syst. Sci., 15, 569-584, doi:10.5194/hess-15-569-2011, 2011. 
Villarini, G., Mandapaka, P., Krajewski, W., and Moore, R.: Rainfall and sampling uncertainties: A rain gauge perspective, J. Geophys. Res. Atmos., 113, D11102, doi:10.1029/2007JD009214, 2008.

Vischel, T., Lebel, T., Massuel, S., and Cappelaere, B.: Conditional simulation schemes of rain fields and their application to rainfallrunoff modeling studies in the Sahel, J. Hydrol., 375, 273-286, 2009.

Wackernagel, H.: Multivariate geostatistics: an introduction with applications, Springer, 2003.

Webster, R. and Oliver, M.: Geostatistics for environmental scientists, Statistics in practice, John Wiley \& Sons, 2001.
Weerts, A. H. and El Serafy, G. Y. H.: Particle filtering and ensemble Kalman filtering for state updating with hydrological conceptual rainfall-runoff models, Water Resour. Res., 42, 1-17, doi:10.1029/2005WR004093, 2006.

Willems, P.: Stochastic description of the rainfall input errors in lumped hydrological models, Stoch. Environ. Res. Risk Assess., 15, 132-152, 2001.

Zawadzki, I.: Errors and fluctuations of raingauge estimates of areal rainfall, J. Hydrol., 18, 243-255, 1973. 